Please do not remove this page

RMIT

UNIVERSITY

\title{
Video annotation for collaborative connections to learning: case studies from an Australian higher education context
}

Lemon, Narelle; Colasante, Meg; Corneille, Karen; Douglas, Katherine

https://researchrepository.rmit.edu.au/esploro/outputs/9921858904801341/filesAndLinks?institution=61RMIT_INST\&index=null

Lemon, N., Colasante, M., Corneille, K., \& Douglas, K. (2013). Video annotation for collaborative connections to learning: case studies from an Australian higher education context. In Increasing Student Engagement and Retention using Multimedia Technologies: Video Annotation, Multimedia Applications, Videoconferencing and Transmedia Storytelling (Cutting-edge Technologies in Higher Education, Volume 6) (pp. 181-214). Emerald Group Publishing. https://researchrepository.rmit.edu.au/discovery/fulldisplay/alma9921858904801341/61RMIT_INST:Resea rchRepository

Document Version: Accepted Manuscript 
Thank you for downloading this document from the RMIT Research Repository.

The RMIT Research Repository is an open access database showcasing the research outputs of RMIT University researchers.

RMIT Research Repository: http://researchbank.rmit.edu.au/

\section{Citation:}

Lemon, N, Colasante, M, Corneille, K and Douglas, K 2013, 'Video annotation for collaborative connections to learning: case studies from an Australian higher education context' in Laura A. Wankel, Patrick Blessinger, Jurate Stanaityte, Neil Washington (ed.) Increasing Student Engagement and Retention using Multimedia Technologies: Video Annotation, Multimedia Applications, Videoconferencing and Transmedia Storytelling (Cutting-edge Technologies in Higher Education, Volume 6), Emerald Group Publishing, United Kingdom, pp. 181-214.

See this record in the RMIT Research Repository at:

http://researchbank.rmit.edu.au/view/rmit:22330

Version: Accepted Manuscript

Copyright Statement: (c) 2013 Emerald Group Publishing Limited

Link to Published Version:

http://trove.nla.gov.au/version/195728465 


\title{
VIDEO ANNOTATION FOR COLLABORATIVE CONNECTIONS TO LEARNING: CASE STUDIES FROM AN AUSTRALIAN HIGHER EDUCATION CONTEXT
}

Narelle Lemon, Meg Colasante, Karen Corneille and Kathy Douglas, RMIT University, Melbourne, Australia.

\begin{abstract}
This book chapter introduces an emerging innovative technology known as MAT (Media Annotation Tool). MAT is an online tool that allows students to annotate video thus improving student engagement and reflection. This chapter outlines the history of the development of this tool and provides analysis of data provided from a range of course integrations. From idea inception the goal was to render video active and collaborative for learning rather than traditional passive learning. In the multiple-case study it was found that students reported higher engagement/satisfaction with MAT in cases where there was learner-to-learner collaboration, teacher feedback and assessment linkage. This chapter focuses on the undergraduate cases of the study, from the disciplines of teacher education, medical radiation and chiropractic, and also references a postgraduate case from the discipline of law. The data from these cases points to the success of MAT as dependent on two key factors: learning design and the technical effectiveness of the MAT technology.
\end{abstract}

\section{INTRODUCTION}

The growth in the use of e-learning initiatives in Australian universities provides programs and teachers with the choice of a variety of online tools that facilitate student learning (Herrington et al 2010). In this chapter we present a case study on the evolution of a new online tool, the media annotation tool (MAT). This new online tool provides a web-based interface that allows opportunity for uploading video that then can be annotated. The design, development and implementation of this tool may be interesting to other institutions, as the "lessons learnt" with this new technology are transferrable across other learning tools of a similar nature, particularly artefact-centred collaborative learning technology. This tool was developed at RMIT University in Victoria, Australia. 
This chapter traces the development of MAT and its application to a variety of learning contexts, from idea inception in 2005, to design and trial stages, a pilot in 2009, and finally multiple disciplinary use in 2011. At each of these stages - from design through to cross-discipline implementation - student feedback has been integral to guide the next steps. MAT requires teachers in higher education learning contexts to adapt new modes of technology-supported collaboration with and for students in a higher education environment. Issues addressed in this chapter include technology deployment contexts, and examination of the outcomes of up-take in a variety of discipline learning environments across one Australian university.

While media annotation tools are relatively new in higher education and training (e.g. Glover, et al., 2007), MAT is differentiated by a structured annotatable learning cycle that allows for discussion to be directly anchored to segments of media, keeping analysis activities focussed but collaborative. While found to be innovative in both media design (Colasante \& Fenn, 2009) and learning application in a 2009 pilot study (Colasante, 2010; Colasante, 2011a), it is the application into multi-contextual settings across academic disciplines, sectors and student cohorts during 2011 that has allowed for comparison of innovative learning and teaching designs. The use of MAT across this multidisciplinary research project involved examining these designs in their efforts to engage higher education students at various levels, allowing them to transfer theory and practical application associated to their specific disciplines. This chapter discusses the MAT learning design, pedagogy and data, gathered from both the teachers and students, that demonstrates the educational benefits of MAT. All participants in this project were seen as active learners in how MAT was being used for alternative and appropriate models of learning and assessment. Strong connections are made to work-relevant learning, supported in most cases by industry partnerships via input into the learning process.

\section{THE DEVELOPMENT OF ANNOTATABLE VIDEO AS A LEARNING TOOL}

In learning and teaching design in tertiary education it is becoming more important to engage students with innovative pedagogy, using such tools as MAT. Increasingly there is student engagement with digital interfaces, and many higher educational policies and practices support new technologies. While digital natives are reported to thrive in technologically mediated 
environments and interfaces (Tapscott, 1998; Starkey, 2011), this chapter acknowledges varying levels of learner capabilities as digital natives (Herrington \& Herrington, 2006; Howe \& Strauss, 2003; Oliver \& Goerke, 2007; Berger, 2007; Keengwe, 2007; Bennett, Maton, \& Kervin, 2008; Helsper \& Eynon, 2009; Corrin, Bennett \& Lockyer, 2010; Lemon, 2012). MAT is an interface that has been inspired by popular social networking features such as that seen with Facebook and Twitter to engage students to explore alternative ways to view video on learning, work-related practices, and unpacking of theory associated to specific disciplines and thus annotate to connect to reflective and metacognitive thinking. It therefore is vital in the evolving design and pedagogy of MAT to acknowledge the features of twenty-first century learners who are increasingly challenging the learning and teaching strategies implemented in higher education based on teacher-centered delivery or top-down hierarchical command and control structure of the past.

Video plays a significant role in today's education (Kaufman, 2009; Dong, Li \& Wang, 2010). Video (or television) can provide a passive learning medium, however, if enhanced can become effective in assisting student learning. The key is to incorporate student engagement through “interactive, viewer-paced watching combined with compositional power ... [to] lead to high levels of reflective thought, particularly if the interaction is constructed by a creative author" (John \& Wheeler, 2007, p.4). To enable media to move from "narrative" or "linear presentational media" (Laurillard, 2002, p.91) such as viewing video to something more engaging for learning, Laurillard (2002) also recommended complementing with other media forms to render the resources interactive, and allow exploration, linkage across topics, and to be able to "follow their own line of investigation" (p.124).

With the increasing growth of video data, it is envisioned that there will be more extensive research conducted to effectively segment, annotate, and access these data (Dong, Li \& Wang, 2010). However, due to the unstructured and linear features of videos, students may have difficulties in locating a specific piece of information in a video as well as challenges in the linkage of ideas. Media annotation software interfaces and the annotation process do support students in such situations and with some guidance can usually move forward with success. Video annotation of students' efforts or video provided by teachers can represent authentic learning when providing simulations of the "real world" of work. Video can provide a simulation 
that engages students and asks them to reflect on a work related task (Colasante, 2011b). The more explicit connections between higher education curriculum content and the video content itself, the more relevant the video interactions become for the viewer. Additionally, providing analysis categories provides some structure for students to make sense of the content (Krottmaier \& Helic, 2002, in Colasante \& Fenn, 2009), which in MAT is achieved by using teacher created 'Marker Types'.

Next we describe the history of the development of MAT from idea inception to the present multidisciplinary applications of this online tool.

\section{THE STORY OF MAT'S EVOLUTION}

MAT has journeyed through a number of iterative processes, building on input from teachers, students and both learning and technical support professionals. Below is a diagram of these stages - moving from design through to cross-discipline implementation.

Figure 1: Timeline of MAT's evolution

At the initial stage of development, before the tool reached pre-production stage, three branches of thinking and literature research were undertaken and cross-pollination between these branches occurred. The first branch formed a pedagogical perspective, identifying possible micro learning steps to enable building toward a cycle of learning involving meaningful engagement with media. The second branch was from a technological perspective of functional development possibilities. Both of these two branches fed into the third, that of interface design.

With ever increasing digital resources available to contemporary students, it was important that MAT did not simply become a passive 'transmission' type of resource or a technology that stymied learning. MAT goes beyond adding the medium of text to video to make it more interactive; it offers a flexible structure or framework for the text via multiple options so that 
learning has the opportunity to be guided by a light or heavy hand, or somewhere in between, as appropriate to the learning objectives. These options include:

- learner flexibility of where text is added to the video timeline (via creating Markers, see Figure 2: A)

- teacher (or learner) flexibility on categories of analysis (i.e.: establishing Marker Types; Figure 2: B)

- learner 'voice' or perspective on giving each Marker a title meaningful to self and/or others (Figure 2; C)

- teacher flexibility on which discussion/annotation panels to employ in the activity cycle, and how to guide their use (i.e.: uses of these regardless of their generic titles of 'Notes' and 'Comments' (Figure 2: D), plus 'Conclusion', 'Teacher Feedback' and 'Final Reflections')

- learner 'voice'/perspective for text entries into the annotation panels employed (Figure 2: E).

Figure 2: Screen capture of MAT as used in Education (Visual Arts); labelling added coordinated to text above

Additionally, MAT offers teacher and/or learner flexibility in how the learning in MAT translates back into professional practice (student placement or career), classroom activities, and/or assessment. Technologically, by being web-based MAT can be opened in any of the popular browsers (Chrome, Firefox, IE, etc.), but is limited for mobile device access due to Flash $^{\mathrm{TM}}$ support requirements, plus it scales better for larger screens.

The example of MAT use in Education (Visual Arts) offered in Figure 2, shows a snap-shot of a student's annotation of an uploaded video on artworks at her placement primary school. The teacher has provided the analysis categories (B) as 'Creating and Making'; 'Exploring and Responding'; 'Arts Learning and Teaching'; 'Medium(s) used to produce art work'; 'Elements of Art'; Pedagogy'; and 'You as an Artist'. The student has marked and annotated the video in 
four places, which she has categorised under the first two of these categories, evidenced as blue and red markers across the video timeline (A). The student has named her markers (C) and entered notes $(\mathrm{E})$ both of which will stay anchored to the segments of video that she chose to annotate.

For the Education (Visual Arts) students, MAT involved mainly individual activity—although the students did this in class time enabling face-to-face collaboration-while some of the other cases had different learning design requirements, as can be seen in Table 1. For example, in some of these cases MAT video content actively involved respective industry representatives (Juris Doctor, Chiropractic, Medical Radiations), plus one application of MAT involved an industry representative providing direct student feedback in MAT (Juris Doctor).

\section{Table 1: MAT case integrations}

In a study of thirty different online and blended learning environments Bekele (2010) noted flexibility as both a factor of motivation and a factor of satisfaction. However, learning motivation is not guaranteed by providing flexibility. It is a skill for teachers to encourage students' motivation in learning before their intrinsic motivation is activated, which is not usually until a topic has progressed (Biggs \& Tang, 2007). MAT does not automatically stimulate motivation, as "[w]hile the design and use of MAT fosters active learning, the other element of student engagement - motivation - seems to have become lost in implementation in some of the cases" (Colasante \& Lang, 2012).

The boxes below provide a progressive summary of the development of MAT at RMIT University.

\section{Key stakeholders test the pre-production MAT design}

User testing of the initial MAT design was conducted using an illustrative but semi-interactive representation of MAT, via a page turning PDF file representing steps a student might take through the tool (Colasante \& Fenn, 2009). Two focus groups volunteered to provide feedback on the MAT design from student cohorts where the teachers were keen to integrate MAT for 
specific learning purposes; they had intrinsic motivation to see a good final product. The first, undergraduate Physical Education (PE), expected to use MAT for analysis of videos of their own PE teaching practice. The second, undergraduate Applied Communication students anticipated using MAT to analyse online audio of student-produced radio interviews. The focus groups were asked to provide feedback via two brief questionnaires; the first harnessing their initial impressions of the design, the second after they had open-group discussions with the designers. This iterative questioning provided valuable feedback on how the tool design could be improved, plus affirmed a number of design decisions. Some features were subsequently improved as a direct result of this user-tester feedback on the initial design.

\section{ก}

\section{The first MAT trial}

When the tool was near completion, a trial was organised. The first student cohort to trial MAT in learning was a class of Diploma of Medical Laboratory (vocational/college) students and their teacher. The students used MAT for two separate classroom activities to analyse videos of electrophoresis (medical science) procedures. Each set of MAT activities was to prepare the students for hands-on practical laboratory procedures, which were demonstrated in teacherproduced videos uploaded to MAT. They were asked - in pairs and in two micro-learning stages - to categorise and annotate each video, in particular to recognise equipment and solutions, and then procedural steps and hazards. The trial enabled testing of MAT functionality across two authentic user situations, under the supervision of the key web developer (MAT programmer) and the MAT designers, allowing direct assistance to the students as technical issues arose, plus enabling direct observation of the user experience and fine-tuning of the tool in response to this. Additionally, students completed feedback surveys that also contributed to improvements. 


\section{The pilot study}

The next step involved a formal pilot study of MAT as integrated into a higher education learning semester. This single-case study examined the integration of MAT into a third-year undergraduate Physical Education (PE) teaching course (subject). It explored the use and effectiveness of MAT in learning, investigating how this online learning environment might be used by students and teachers to support their intended learning outcome: to critically reflect on and evaluate their PE teaching practice. The case provided opportunities to gather baseline data before wider uptake of the tool, and to trial a research framework that was designed to scale-up to a multiple-case study.

The case provided both encouraging and useful findings (Colasante, 2011a). The study illustrated that MAT was largely effective for their intended learning, to critically reflect and evaluate their teaching practice. The students achieved this by recording videos of their own teaching practice and uploading them within their small peer group area in MAT. They viewed their videos and selected and categorised sections with pre-determined teacher categories and typed in notes. A conductor-of-sorts, the teacher provided a timing structure the students were to follow, to enable individual analysis followed by collaboration within their small groups, such as a 'due date' for marking up own videos followed by peer feedback on the analysed video sections, then conclusion writing. The teacher provided feedback within MAT, deliberately targeting areas of highest impact to each student's development. The students reviewed their annotation cycles repeatedly and then transferred their findings within MAT into a reflective report for assessment submission. Overall, the results encouraged wider use of MAT across other disciplines to further test learning effectiveness (Colasante, 2010). Additionally, technical modifications were recommended for MAT as a result of the pilot study, some of which were adopted.

\section{Multiple-case study across disciplines and sectors}

Employing the research framework as established and tested in the pilot case study, MAT was next examined across multiple cases. This collaborative project involved actively using MAT for work preparation/analysis activities, across a range of disciplines and tertiary sectors. These included postgraduate Juris Doctor (law); undergraduate Education (Literacy), Education (Visual Arts), Chiropractic, and Medical Radiations; vocational Property Services (three cohorts) and Audio-visual Technology. In total, nine cases across six disciplines where examined, and this 
chapter refers to the five cases involved in the project from the higher education context.

An earlier work-in-progress report on the multiple-case study looked at four of the higher education cases with a focus on the relationship of learning design to student engagement (Colasante \& Lang, 2012). It was found that students reported higher satisfaction in cases where there was learner-to-learner collaboration, teacher feedback and assessment linkage, plussomewhat surprisingly — where teachers provided videos within MAT rather than student video generation and upload. The latter was further contextualised by reported difficulties and/or excessive time consumption in video uploading. This chapter continues the focus on student engagement with MAT, but specifically widens the data range to further explore these issues, plus includes reference to the fifth higher education case, the postgraduate Juris Doctor cohort.

\section{METHODOLOGY: MULTIPLE CASE STUDY APPROACH}

Following the successful MAT pilot study in 2009 a larger mixed method multiple-case study was established to examine further MAT's application in learning and teaching across varied contexts. The evaluation framework was trialled in the pilot-case study, and benefited from minor design adaptation for the multiple cases shared in this chapter. Multiple-case studies are commonly designed to study innovations in education, including researching the integration of new educational technology (Yin, 2009).

The multiple-case study involved using MAT for reflective practice, content specific analysis, professional practice and work preparation analysis activities in a range of courses across the tertiary sectors. This chapter refers to the five cases involved in the project from the higher education context within one Australian university and includes courses from the Juris Doctor, Teacher Education courses of Visual Arts and Literacy, and health sciences courses from the Medical Radiations and Chiropractic programs. Table 1 displays these diverse areas involved in the study and indicates the foci for learning and teaching, and Table 2 displays class sizes, and breakdown of gender for the student participants. The 244 student participants of the higher education cases were involved in using MAT within their study and were invited to evaluate its 
effectiveness and how the interface addresses specific objectives. From this, 161 students across the cases volunteered to participate in the study.

\section{Table 2: Higher education MAT cases - Class size and gender mix}

Student research participants from each case were involved in a two-part survey that allowed for collecting data pre and post MAT use. The survey participation levels are provided in Table 3. In particular for the focus of this discussion, pre-survey data provided basic student demographics, student ICT access and perceived skill levels, and whether they liked learning online in general. The post-survey data provided student opinions on a range of questions on whether they liked MAT in their learning, and what features of MAT they found most helpful or most unhelpful. The surveys comprised a range of quantitative (mainly Likert-styled) and qualitative or open question styles.

\section{Table 3: Higher education student surveys completed}

Additionally, a number of teachers and students and one expert/industry representative were involved in the interactive process interviews that were held after MAT was administered. The interviews involved the interviewee first demonstrating and explaining their use of MAT under observation, followed by a semi-structured interview. This was helpful in triangulating the data even though student participation numbers were low overall. The number of interviews conducted across cases is shown in Table 4, each of which was audio-recorded with participant permission.

\section{Table 4: Higher education interviews conducted}

The main limitation in preliminary MAT studies (design stage, trial, and pilot implementation) involved small participation numbers due to data collection concentration in single or few cohorts, rather than low percentage of volunteer participants. While the recent study - the multiple-case study - extended across a number of student cohorts of various disciplines, the limitations still centred on participation numbers. However, this was related to uneven student

participation across the cohorts, which ranged from moderately-low to very high per cohort for 
the surveys, but very low to moderate for the student observations and interviews. The nature of voluntary participation meant that student participation would be unpredictable. However, it must be noted that the teacher participation was very high, with a $100 \%$ participation rate for teachers who were early adopters of MAT.

Ethics approval was granted to conduct this research prior to data collection. All participants were invited to participate, and were ethically respected in that their responses were harnessed during the teaching semester but not during class time, and accessed post-semester. This approach meant that there was no impact on assessment or curriculum timelines.

\section{SELECTED FINDINGS}

The following analysis draws primarily from the student survey data, supported by interview material from teachers and students. Firstly, pre-survey material including student characteristics and familiarity with computers and online learning is discussed. Secondly, results from a survey administrated after student engagement with MAT are analysed, including use, student assessment of the tool and self-assessment of learning. Finally, data from students and teachers gathered via interactive interviews related to engagement in learning is discussed.

\section{The survey}

Surveys were administered to all students prior to the introduction of MAT and following its use in their course. The pre-survey collected demographic information, activity levels, access details and attitudes to online learning. The post-survey allowed students to give feedback about the use of MAT in their course. The overall response rates were $52 \%$ for the pre-survey and $40 \%$ for the post-survey, with the Education (Literacy) group having the highest response rate across the cases. Unfortunately due to a timing error the Juris Doctor students were not able to fully participate in the post-survey and only two responses were received. Survey participation details are shown in Table 3 (methodology section).

\section{Pre-survey}


The demographic details for each of the cases were harnessed in the pre-survey. There were a small number of students in each case who completed the post-survey without having completed the pre-survey so their demographic information appears as unknown.

Apart from Juris Doctor (the postgraduate case), each of the cases had a mainly younger student representation with the majority of students being aged 25 and under. For gender distribution (as tabled in the methodology section), in Education and Medical Radiation there was a higher representation of females; whereas in Chiropractic and the Juris Doctor, where the information was known, the gender split was fairly even.

In each of the cases the majority of students nominated English as their first language. Of the 22 students across disciplines who stated that their first language was not English, their first language stated was Chinese $(n=9)$, Vietnamese $(n=3)$, Korean $(n=2)$, Swahili $(n=1)$, French $(n=1)$, Greek $(n=2)$, Arabic $(n=1)$, Shona $(n=1)$, Hakka $(n=1)$ and Dari $(n=1)$. Where the country of birth was known, the majority (76\%) were born in Australia. Other countries listed included China (7\%), Vietnam (4\%), South Korea (2\%), Hong Kong (2\%), Malaysia (2\%), Afghanistan (1\%), Kenya (1\%), New Zealand (1\%), Mauritius (1\%), Greece (1\%), Iraq (1\%), Singapore (1\%), Zimbabwe (1\%) and England (1\%).

In summary, students were more often female, under 25, and born in Australia.

The second section of the pre-survey dealt with internet access, ability and attitudes to online learning. For each of the cases all students had daily access to computers and the internet, thus enabling all the opportunity to use MAT. Attitudes towards online learning in general were very favourable with over $90 \%$ in each case agreeing — in full, or some of the time - that they liked learning with resources and activities online. This positive attitude meant that students were likely to be receptive to using MAT in their course (however, some variance occurs later when the questions become more specific towards online learning in their own courses).

When asked about their computer skill level the most confident were the Juris Doctor and Medical Radiations students; the least confident were the Education (Visual Arts) students. 
Possible reasons for this are that the Medical Radiation students would need to have good technical skills for their course, and that Juris Doctor students tended to be mature age and quite possibly using computers regularly in their work. The most likely place that students from all cases were going to access MAT was at home. The second most likely access venue was at university for the undergraduate students and at work for the postgraduate students (Juris Doctor).

Students were also asked about their preferred learning style and the most popular response given by Education (Literacy and Visual Arts) and Juris Doctor students was "listening and talking", whereas for the Chiropractic case it was "moving or manipulating", and for the Medical Radiation case "watching or reading”. These responses, suggesting 'aural', 'kinaesthetic', and 'visual' preferred learning styles respectively, are not surprising given the vocational training needs of each case.

Responses to a further question on attitude towards online learning (Figure 3) was consistent to those from an earlier question and revealed strong support for online learning in each of the five cases - especially Medical Radiation. There was however almost one-quarter of Education (Visual Arts) students who were not keen on online learning and some ambivalence amongst the Education (Literacy) students.

Figure 3: I do not like using online learning at all in my studies.

\section{Post-survey}

The post-survey results which follow do not include the Juris Doctor cohort due to a low number of responses $(n=2)$. Results (Figure 4 ) for the usage of MAT showed that the Chiropractic students were the most regular users on a weekly basis. The other cases tended to use MAT on a more irregular basis and the biggest group for class time only use were the Education (Visual Arts) students. The most common amount of time spent in one episode was 15-30 minutes across all cases (Figure 5).

Figure 4: How frequently did you use MAT this semester? 
Figure 5: How long, on average, did you spend using MAT in any one episode?

In terms of which features of MAT were accessed (e.g. watched or read), Chiropractic students were the most avid users with more than half of this group accessing all but four of the ten features listed on an Often/Very Often basis. In contrast, the other three cases tended to select "Never" or "Sometimes" for a range of each of the features.

A number of rating scale (Strongly Disagree to Strongly Agree) items was included in the postsurvey to elicit attitudes towards using MAT in their courses. Results for items that were common for each case appear below.

The group of students who enjoyed using MAT most was the Chiropractic students; conversely, Education students enjoyed it the least (Figure 6). Perhaps not surprising given in the pre-survey the Education students had given the lowest support to online learning.

There was also the added requirement of the Education students to produce and upload their own videos, in contrast to the professionally produced videos for Chiropractic and Medical Radiation cases. This introduced an extra level of technical complexity, which for some was likely a cause of frustration. Another possible reason for the higher satisfaction amongst the Chiropractic and Medical Radiation cases was that the video content was highly relevant to their vocational training needs, and that there seemed to be a more systematic approach in the administration of MAT e.g. defined group activities and teacher feedback.

Figure 6: I liked using MAT in my learning activities.

Responses (Figure 7) to a similar question are consistent with these findings. 
LEMON, COLASANTE, CORNEILLE \& DOUGLAS

Figure 7: The use of MAT in this course has hindered my learning experience compared to traditional learning

More than half of the students - except those in Education (Visual Arts) - felt comfortable in using MAT (Figure 8); almost $40 \%$ of the Education (Visual Arts) cohort did not.

Figure 8: I felt comfortable communicating through MAT for the activities.

There was a strong level of agreement (Figure 9) by the Chiropractic and Medical Radiation students in relation to the way MAT allowed for communicating and collaborating with other students. This could be due to the way that MAT was utilised in each of the cases. Indeed in Chiropractic it was a requirement that students worked in groups and nominated a leader to form conclusions for a patient diagnosis.

Figure 9: Using MAT in this course allowed me to communicate and collaborate with other students, and with my teacher, in a way that was helpful to my learning

When asked about which issues relating to MAT were most helpful for learning the responses covered: relevance to theory; collaboration; use of markers; viewing and commenting on videos; and feedback. Summaries by case follow:

- Chiropractic: Many of the comments related to how beneficial it was to see real life examples and how it linked back to theory. Other comments included favouring the online collaboration, ability to view and review, and use of markers in clinical findings.

- Medical Radiations: The most common response was being able to see a professional critique of images. Other comments included ability to play/replay, annotate, and reinforcing concepts. 
- Education (Visual Arts): The majority of comments were concerned with students appreciating viewing and commenting on the videos, and liking to use a new ICT resource.

- Education (Literacy): Most of the responses related to appreciating the feedback and interaction with peers.

When asked about which issues relating to MAT were least helpful for learning the responses covered: problems associated with the administration of MAT; time issues; unclear purpose or relevance; and technical glitches. Summaries by case follow:

- Chiropractic: Some of the responses related more to the administration of MAT in the class e.g. problems with group membership, or only one clinical case to review, rather than its features. Responses more concerned with MAT functionality were: lengthy time it took to use, complexities, and repetitiveness.

- Medical Radiations: There were a range of responses which included lack of time, poor quality of video, use confusion (which also relates back to video quality in that some didn't play the video in the MAT interface), reliance on computer and internet access, and lack of opportunity to do own critiquing.

- Education (Visual Arts): Many of the comments were about navigation and uploading difficulties; one student did not understand the relevance of MAT use in the Visual Arts.

- Education (Literacy): Most of the responses concerned navigation and uploading difficulties.

\section{Correlations}

A bivariate correlation analysis (Spearman's rho) using rating scale items (Strongly Disagree to Strongly Agree) in the post-survey was conducted to detect what drove engagement with MAT. Spearman's rho is appropriate for examining relationships between such ordinal level Likert scale items (de Vaus, 2002), and even though the number of respondents for each case was small the test of significance takes into account the sample size. 
All rating scale items in the post-survey were included in the analysis, with the item "I liked using MAT in my learning activities" as the leading item. The case disciplines were analyzed separately because of the different uses of MAT and it was of interest to see if there were any significant relationships that were common across the cases (See Table 5 in Appendix).

Across all cases a significant relationship existed between liking MAT and 'Using MAT allowed me to communicate and collaborate with other students, and with my teacher, in a way that was helpful to my learning' indicating that the feedback and collaboration features of MAT helped engage students. Similarly, for all cases, significant correlations existed between liking MAT and recommending its use to others. Results for each case follow.

\section{Chiropractic}

Correlations between 31 post-survey items and "I liked using MAT in my learning activities" were analysed and the significant results are shown in Appendix.

A significant positive relationship existed between liking MAT and 17 other items, with the strongest two correlations being:

- MAT was an excellent tool for viewing and annotating media. $\left(\mathrm{r}_{\mathrm{s}}=.755, \mathrm{p}<.01\right)$

- From my experiences of using MAT, I would recommend it for other students to use. $\left(\mathrm{r}_{\mathrm{s}}=.688, \mathrm{p}<.01\right)$

These results show that those who liked using MAT would recommend it to others and saw it as being useful as a learning tool. (The converse also holds true.)

A significant negative relationship existed with liking MAT and 4 other items with the strongest two being:

- I would have preferred not to use MAT. $\left(\mathrm{r}_{\mathrm{s}}=-.716, \mathrm{p}<.01\right)$

- The use of MAT in this course has hindered my learning experience compared to traditional learning methods. $\left(\mathrm{r}_{\mathrm{s}}=-.571, \mathrm{p}<.01\right)$

This indicates that students liking MAT also supported the use of MAT in their course.

\section{Medical Radiations}


Correlations between 31 post-survey items and "I liked using MAT in my learning activities", an indicator of engagement, were analysed and the significant results are shown in Appendix.

A significant positive relationship existed between liking MAT and 13 other items, with the strongest two correlations being:

- From my experiences of using MAT, I would recommend it for other students to use. $\left(\mathrm{r}_{\mathrm{s}}=.646, \mathrm{p}<.01\right)$

- Having access to MAT enhanced my learning experience in this course. $\left(\mathrm{r}_{\mathrm{s}}=.571, \mathrm{p}<.01\right)$.

Like Chiropractic, this shows a strong relationship between liking MAT and its usefulness as a learning tool.

A significant negative relationship existed with liking MAT and 3 other items with the strongest two being:

- I would have preferred not to use MAT $\left(\mathrm{r}_{\mathrm{s}}=-.651, \mathrm{p}<.01\right)$.

- I would have preferred to have face to face discussions about the learning instead of using MAT. $\left(\mathrm{r}_{\mathrm{s}}=-.509, \mathrm{p}<.01\right)$.

This indicates that students who liked using MAT also supported the use of MAT, and preferred using an online tool rather than face to face delivery. (The converse also holds true.)

\section{Education - Literacy}

Correlations between 41 post-survey items and "I liked using MAT in my learning activities" were analysed and the significant results are shown in Appendix.

A significant positive relationship existed between liking MAT and 12 other items, with the strongest two correlations being:

- Using MAT allowed me to receive encouraging support. $\left(\mathrm{r}_{\mathrm{s}}=.833, \mathrm{p}<.01\right)$

- The amount of interaction with my peers (fellow students) in MAT was appropriate.

$$
\left(\mathrm{r}_{\mathrm{s}}=.781, \mathrm{p}<.01\right)
$$

This finding is different to the other cases, indicating that the strong relationship between liking MAT and group interaction and support was an important issue for the Education (Literacy) 
students. Further examination of the data revealed that there was a high level of disagreement with the support item (60\%) and dislike of MAT (also close to 60\%), so the lack of support was a factor in their low engagement with MAT.

A significant negative relationship existed with liking MAT and 2 other items:

- I would have preferred not to use MAT. $\left(\mathrm{r}_{\mathrm{s}}=-.733, \mathrm{p}<.01\right)$

- I was very unsatisfied using MAT. $\left(\mathrm{r}_{\mathrm{s}}=-.642, \mathrm{p}<.01\right)$

This indicates that students liking MAT also supported the use of MAT in their course, and that there was a level of consistency with responses for liking MAT and satisfaction with MAT.

\section{Education - Visual Arts}

Correlations between 35 post-survey items and "I liked using MAT in my learning activities" were analysed and the significant results are shown in Appendix.

A significant positive relationship existed between liking MAT and 8 other items, with the strongest two correlations being:

- From my experiences of using MAT, I would recommend it for other students to use.

$$
\left(\mathrm{r}_{\mathrm{s}}=.787, \mathrm{p}<.01\right)
$$

- Using MAT allowed me to be involved in activities that are relevant to my eventual professional practice. $\left(\mathrm{r}_{\mathrm{s}}=.699, \mathrm{p}<.01\right)$

As with the previous cases, this shows a strong relationship between liking MAT and its usefulness as a learning tool; especially in this case its value in relevant professional practice. A significant negative relationship existed with liking MAT and "I was very unsatisfied using MAT" $\left(\mathrm{r}_{\mathrm{s}}=-.575, \mathrm{p}<.01\right)$ indicating a consistency in opinion.

\section{Interactive Process Interviews}

The interactive process interviews with students, teachers and the industry expert were analysed using NVivo and the results for a selection of items relevant to engagement follow. These include opinions of effectiveness of MAT for learning engagement, what they liked or 
experienced as barriers in their learning with MAT, and the role of assessment in their MAT related activities.

Students were asked about the effectiveness of MAT for engaging in their work-relevant learning and assessment activities. The most common types of responses were that it was a relevant activity; was helpful in their learning; and that they liked how it was interactive. Suggestions such as: needing a purpose, and needing to be part of the assessment, were also raised as engagement factors.

"Yeah, it's applying your knowledge, so you feel like you're actually able to do what you're learning to do."

"For my course I found watching the video and identifying the marker types for the first video was really, that was probably my favourite and most interesting."

When teachers were asked a similar question the answers were not that dissimilar, with relevant activity, and helpful for learning, as being the most common responses. They also saw the Marker features, giving feedback and the interactive nature of MAT as being useful for engaging the students. Concerns were raised by a couple of teachers about the amount of time involved, and about some of the technical glitches.

Answers given by students about what they liked most about MAT included how they found it helpful in their learning especially the ability to watch/re-watch videos; the use of markers; and reading the comments and feedback of others.

"But the most useful part of it for me was giving feedback, because the entire time, I was thinking about my own book as well and I was thinking about what makes a good book..."

"...getting feedback is the most motivating thing..." 
Barriers for engagement with MAT were also raised in the interviews and the responses could be categorized into three areas:

- Technical e.g.: upload problems; functionality (including broken links); not user friendly; and navigation.

- Implementing MAT e.g.: training and support; time constraints; instruction not clear; group work; lack of continuous use; wanting more videos; privacy issues; not assessed; and purpose not clear.

- Features of MAT e.g.: marker problems (in particular not being able to make them less than 30 seconds long); lack of comments; or hard to find comments; and poor quality of peer feedback.

The interviews also allowed the issue of assessment to emerge. Across the five higher education cases featured, two cases directly assessed the student activities in MAT. Both the Juris Doctor and the Chiropractic cases used these activities as a minor assessment item for the course with marks allocated. The Juris Doctor students completed their assessable MAT activities early in the semester, while the Chiropractic students' activities continued across the academic semester. Both the Education cases, Literacy and Visual Arts, allowed students to portfolio their progress throughout the semester but neither was directly assessed. For example, the Literacy students publicly presented their completed task of a child's storybook in class, as the summation of their storybook progress and collaboration in MAT.

The Medical Radiations MAT activities, while helpful for eventual professional practice (that was still a few years away for these first year students), did offer examination preparation, which the students were informed of but didn't always find this reason enough to engage. For example, one student offered:

"the reason that I didn't do much is because it didn't have a direct assessment component. ... Probably if I was a more diligent student I would've done more ..." 
Therefore, the Chiropractic cohort was the only case to have a semester-wide assessment component to the learning requirements in MAT, while the Juris Doctor included a start-ofsemester MAT assessment component.

In the next section of this chapter we discuss the implications of this selected data.

\section{IMPLICATIONS}

A high proportion of students across all cases was supportive of using an online learning tool, and had the requisite access and skills to use MAT in their courses. Higher satisfaction with MAT was experienced in cases where there was a requirement for collaboration with other students to achieve goals, included teacher feedback, and formed a part of the assessment. Another factor was that satisfaction was higher where teachers provided videos within MAT rather than where the students generated and uploaded the videos. This may be due to students' time, effort and vulnerability in generating their own material, and the extra level of technical complexity that for some was a cause of frustration. The cases with higher satisfaction were Chiropractic and Medical Radiation where the task designs were more structured than in the two Education cases. Drivers of engagement were explored using correlations, with the feedback and collaboration features of MAT coming across as a strong factor for all cases. For instance, there was a significant relationship between endorsement (liking) of MAT by students and the use of MAT to aid learning through collaboration with fellow students and teachers. This shows that in this study the feedback and collaboration features of MAT helped engage students.

The effectiveness of MAT for engaging in work-relevant learning and assessment activities was examined and the most common factors for its effectiveness included that it was a relevant activity, was helpful in their learning, and it was interactive. However, needing both a purpose and to be part of the assessment, were also raised. This is an important finding of this study as it demonstrates that future teacher adopters of MAT need to clearly explain the reason for adoption to students prior to use. It may also be necessary to include MAT as an assessment task as from this study learner engagement (or perhaps motivation to engage) is heightened when MAT is 
assessed. The most successful use of MAT in this study, the Chiropractic application, included direct assessment of activities in MAT.

Clear benefits of MAT, according to student perceptions, related to the authentic nature of the use of this tool in learning. Students perceived MAT as beneficial due to the "real life" nature of the simulations and the ability to integrate theory with practice using the tool. Another feature nominated by students was reflection on learning tasks through viewing and reviewing video. Key to this are the markers that are used in MAT that provide an organising feature for analysing and review. Video annotation tools offer the potential to support both the reflection and analysis of one's own video (Colasante, 2011b) and as Luo \& Pang (2010) found in their research, video annotation can allow for the slowing down, repeated viewing and identification of key aspects of the video as a connection to specific content focus. While video has long been used to capture micro-teaching episodes as well as to illustrate and review classroom cases/practices and to review teaching or teachable moments (Rich \& Hannafin, 2009; Schroeter, Hunter \& Kosovic, 2003; Correia \& Chambel, 1999) it is the possibilities of annotation that can assist in extending reflection, connections to curriculum content and professional needs, wants and practices.

Teacher or professionally generated and student generated video has potential in connecting the content to the higher education student preparing to graduate as a professional in their field. In this study student review of material was self-paced through to teacher-guided and included the opportunity to discuss online the video material, drawing on peer, industry and/or teacher input. However, quality and reliability of the technology was a relatively frequent complaint from student participants in the study. The positive attributes of the use of MAT in learning were undermined by technical issues, such as navigation and video uploading difficulties. Apart from technical concerns there were learning and teaching design issues identified including group work issues, lack of time to complete tasks and poor explanation of the task. In the study "liking" MAT is linked with effective engagement. Importantly, technical issues will undermine students' experience of the tool and will impact on students liking MAT. Thus it is imperative that technical concerns be addressed for the success of this learning innovation.

\section{CONCLUSIONS}


The multiple-case study discussed in this chapter shows that MAT provides teachers with an online tool that has the potential to engage students in an authentic learning design that assists in readying students for the world of work. It has seen some success within a number of different disciplines and thus has wide application possibilities in higher education. Student engagement with MAT was particularly dependant on students liking the tool and this in turn was dependant on the learning design and the technological ease of navigation that students experience. Teachers who adopt MAT in the future will need to be aware and pay careful attention to these two concerns. There are many ways that MAT may move forward in the future, to ensure a sustainable and dynamic online tool. The need for ongoing development of this learning and teaching innovation needs to include a focus on critical areas of support for teachers (technical and pedagogical), support for students (learning and technical), and further tool refinement and development. Further data analysis is in progress in this area of sustainability of the tool including support for teachers. Other analysis activities underway include discipline specific single case analysis and artefact analysis of communication activities between students within MAT.

\section{ACKNOWLEDGEMENT}

The authors would like to acknowledge the assistance of G. Marchiori in the graphical preparation of Figures 1 and 2.

\section{REFERENCES}

Bekele, T. A. (2010). Motivation and Satisfaction in Internet-Supported Learning Environments: A Review. Educational Technology \& Society, 13 (2), 116-127.

Bennett, S., Maton, K., \& Kervin, L. (2008). The 'digital natives' debate: A critical review of the evidence. British Journal of Educational Technology, 39(5), 775-786.

Berger, P. (2007). Learning in the Web 2.0 world. [Weblog entry, April 17.] Infosearcher. http://infosearcher.typepad.com/infosearcher/2007/04/learning_in_the.html. Accessed October 31, 2008, from http://www.webcitation.org/5c47GndYr.

Biggs, J., \& Tang, C. (2007). Teaching for quality learning at university: What the student 
does. ( $3^{\text {rd }}$ ed.) Maidenhead \& New York: Society for Research into Higher Education \& Open University Press.

Colasante, M., \& Lang, J. (2012). Can a media annotation tool enhance online engagement with learning? A multi-case work-in-progress report. Proceedings of the $4^{\text {th }}$ International Conference of Computer Supported Education, 16-18 April, 2012, Porto.

Colasante, M. (2011a). 'Using video annotation to reflect on and evaluate physical education pre-service teaching practice'. Australasian Journal of Educational Technology, 27(1), 66-88.

Colasante, M. (2011b). 'Using a Video Annotation Tool for Authentic Learning: A Case Study'. In Proceedings of Global Learn Asia Pacific 2011. (pp. 981-988). AACE.

Colasante, M. (2010). Future-focused learning via online anchored discussion, connecting learners with digital artefacts, other learners, and teachers. In C. Steel, M.J. Keppell \& P. Gerbic, Curriculum, technology \& transformation for an unknown future. Proceedings Ascilite, Sydney 2010.

Colasante , M. \& Fenn, J. (2009). 'mat': A New Media Annotation Tool with an Interactive Learning Cycle for Application in Tertiary Education, World Conference on Educational Multimedia, Hypermedia and Telecommunications (ED-MEDIA) 2009, Vol. 2009: 35463551. Honolulu, HI, USA, AACE.

Correia, N., \& Chambel, T. (1999). Active video watching using annotation. ACM Multimedia '99 (part 2), pp. $151-154$.

Corrin, L., Bennett, S. \& Lockyer, L. (2010). Digital natives: Everyday life versus academic study. Proceedings of the Seventh International Conference on Networked Learning 2010 (pp. 643-650). Lancaster: Lancaster University.

de Vaus, D. ( 2002). Analysing Social Science Data. London: Sage Publications

Dong, A., Li, H., \& Wang, B. (2010). Ontology-driven Annotation and Access of Educational Video Data in E-learning. Retrieved March 16, 2012 from http://www.intechopen.com/books/elearning-experiences-and-future/ontology-driven-annotation-and-access-of-educational-videodata-in-e-learning.

Glover, I., Xu, Z., \& Hardaker, G. 2007. Online annotation - Research and practices. Computers \& Education, 49, 1308-1320.

Helsper, E.J. \& Eynon, R. (2009). Digital Natives: Where is the evidence? British Educational Research Journal 36 (3) 503-520.

Herrington, J., Reeves, T. C., \& Oliver, R. (2010). A guide to authentic e-learning (Connecting with e-learning). New York / Oxon: Routledge. 
Herrington, A., \& Herrington, J. (Eds.). (2006). Authentic Learning Environments in Higher Education. Hershey: Information Science Publishing.

Howe, N., \& Strauss, W. (2003). Millennials go to college. New York: LifeCourse.

John, P. D., \& Wheeler, S. (2007). The Digital Classroom: Harnessing the power of technology for the future of learning and teaching. London: Routledge/David Falmer.

Kaufman, P.B. (2009). On the Utility and Uses of Video in Higher Education. Intelligent television video for culture \& education. Accessed March 15, 2012 from http://www.intelligenttelevision.com/thinkpieces /article/on-the-utility-and-uses-of-video-inhigher-education/

Keengwe, J. (2007). Faculty integration of technology into instruction and students' perceptions of computer technology to improve student learning. Journal of Information Technology Education, 6, 169-180.

Laurillard, D. (2002). Rethinking university teaching: a framework for the effective use of learning technologies. (2nd ed.). London: RoutledgeFalmer.

Lemon, N. (2012). @Twitter is Always wondering what's happening: Learning with and through Social Networks in higher education. (pp. 1- 25). In Patrut, B., Patrut, M., \& Cmeciu, C. (Eds.). S Social Media in Higher Education: Teaching in Web 2.0. Hershey, Pennsylvania, USA: IGI Global.

Luo, G., \& Pang, Y. (2010). Video annotation for enhancing blended learning of physical education. Paper from (ICAIE), 2010 International Conference on Artificial Intelligence and Education, Hangzhou.

Oliver, B., \& Goerke, V. (2007). Australian undergraduates' use and ownership of emerging technologies: implications and opportunities for creating engaging learning experiences for the Net generation. Australasian Journal of Educational Technology, 23, 2, 171-186. Retrieved June 27, 2007 from, http://www.ascilite.org.au/ajet/ajet23/oliver.html

Rich, P.J., \& Hannafin, M. (2009). Promoting Reflection in Teacher Preparation Programs: A Multilevel Model. Journal of Teacher Education January/February, 60(1), 52-67.

Schroeter, R., Hunter, J., \& Kosovic, D. (2003). Vannotea - A collaborative video for indexing, annotation and discussion system for broadband networks. K-CAP 2003 Workshop on Knowledge Markup and Semantic Annotation, Florida, 2003.

Starkey, L. (2011). Evaluating learning in the 21st century: a digital age learning matrix. Technology, Pedagogy and Education, 20(1), 19-39.

Tapscott, D. (1998). Growing Up Digital: The Rise of the Net Generation. New York: McGrawHill. 
LEMON, COLASANTE, CORNEILLE \& DOUGLAS

Yin, R. (2009). Case study research; Design and methods (4th ed.). California: SAGE Publications 


\section{Appendix}

Table 5: Significant bivariate correlations across cases

\section{Items from Post-survey}

$\begin{array}{llll}\begin{array}{l}\text { Medical } \\ \text { Radiations }\end{array} & \text { Chiropractic } & \begin{array}{l}\text { Education } \\ \text { (Visual Arts) }\end{array} & \begin{array}{l}\text { Education } \\ \text { (Literacy) }\end{array}\end{array}$

$.646 * *$

$.688 * *$

$.787 * *$

$.706^{*}$

From my experiences of using MAT,

I would recomm
students to use.

Using MAT allowed me to communicate and collaborate with other students, and with my teacher, $\begin{array}{lll}.461 * * & .531 * * & .647 *\end{array}$

$.602 *$

in a way that was helpful to my learning.

Using MAT allowed me to be involved in activities that are relevant to my eventual professional practice.

\begin{tabular}{|c|c|c|c|c|}
\hline $\begin{array}{l}\text { Using MAT allowed me to be } \\
\text { challenged in an interesting way. }\end{array}$ & $.491 * *$ & $.566^{* *}$ & $.586^{*}$ & \\
\hline $\begin{array}{l}\text { Having access to MAT enhanced my } \\
\text { learning experience in this course. }\end{array}$ & $.571 * *$ & $.539 * *$ & $.582 *$ & \\
\hline $\begin{array}{l}\text { Using MAT allowed me to } \\
\text { communicate and collaborate with } \\
\text { expert(s) in a way that was helpful to } \\
\text { my learning. }\end{array}$ & $.343 *$ & $.415^{*}$ & & $.769 * *$ \\
\hline $\begin{array}{l}\text { I would have preferred not to use } \\
\text { MAT. }\end{array}$ & $-.651 * *$ & $-.716^{* *}$ & & $-.733^{* *}$ \\
\hline $\begin{array}{l}\text { Using MAT allowed me to receive } \\
\text { encouraging support. }\end{array}$ & & $.619 * *$ & $.684^{*}$ & $.833 * *$ \\
\hline I was very unsatisfied using MAT. & & $-.343 *$ & $-.575^{*}$ & $-.642 *$ \\
\hline $\begin{array}{l}\text { I felt comfortable communicating } \\
\text { through MAT for the activities. }\end{array}$ & $.371 *$ & $.499 * *$ & & \\
\hline $\begin{array}{l}\text { The amount of interaction with my } \\
\text { teacher in MAT \&/or about MAT } \\
\text { activities was appropriate. }\end{array}$ & $.547 * *$ & & & $.605^{*}$ \\
\hline $\begin{array}{l}\text { The use of MAT in this course has } \\
\text { hindered my learning experience } \\
\text { compared to traditional learning } \\
\text { methods. }\end{array}$ & $-.410 *$ & $-.571 * *$ & & \\
\hline $\begin{array}{l}\text { After using MAT, I feel I could } \\
\text { communicate my learning in other } \\
\text { situations. }\end{array}$ & & $.449 * *$ & $.602 *$ & \\
\hline $\begin{array}{l}\text { MAT was an excellent tool for } \\
\text { interaction and collaboration with } \\
\text { others. }\end{array}$ & & $.461 * *$ & $.683^{*}$ & \\
\hline $\begin{array}{l}\text { I was satisfied with how MAT } \\
\text { presented (design and layout). }\end{array}$ & & $.496 * *$ & & $.671 *$ \\
\hline
\end{tabular}


MAT was an excellent tool for viewing and annotating media.

The use of MAT in this course has helped me to understand key concepts related to producing better quality $.360 *$ na images.

MAT helped me to analyse technical image quality.

I was satisfied with how to navigate

MAT (moving between the different features).

Using MAT allowed me to reflect on an expert radiographer's critique of a range of upper and lower limb images.

Without the use of MAT, I would not have been successful in this course.

I would have preferred to have face to face discussions about the learning instead of using MAT.

\begin{tabular}{|c|c|c|c|c|}
\hline MAT was difficult to use. & & $-.467 * *$ & & \\
\hline $\begin{array}{l}\text { MAT helped me to analyse } \\
\text { presentations of health problems. }\end{array}$ & na & $.473 * *$ & na & na \\
\hline $\begin{array}{l}\text { The use of MAT in this course has } \\
\text { helped me to understand presentation } \\
\text { and assessment of health problem } \\
\text { presentations. }\end{array}$ & na & $.496 * *$ & na & na \\
\hline $\begin{array}{l}\text { The use of MAT in this course has } \\
\text { helped me to understand presentation } \\
\text { and assessment of headache } \\
\text { conditions. }\end{array}$ & na & $.535^{* *}$ & na & na \\
\hline $\begin{array}{l}\text { Using MAT allowed me to build or } \\
\text { construct meaning from my learning } \\
\text { experiences. }\end{array}$ & & $.566 * *$ & & \\
\hline $\begin{array}{l}\text { Once I was used to MAT, the quality } \\
\text { of learning activities in MAT was } \\
\text { excellent. }\end{array}$ & & $.650 * *$ & & \\
\hline $\begin{array}{l}\text { I liked having access to expert } \\
\text { opinion (e.g.: in video \&or by } \\
\text { commentary). }\end{array}$ & & & & $.580 *$ \\
\hline $\begin{array}{l}\text { I fully utilised the opportunity that } \\
\text { MAT offered. }\end{array}$ & & & & $.591 *$ \\
\hline $\begin{array}{l}\text { MAT helped me to reflect on the } \\
\text { complexity of the drafting processes } \\
\text { involved in writing. }\end{array}$ & na & na & na & $.640^{*}$ \\
\hline $\begin{array}{l}\text { Using MAT encouraged use of } \\
\text { diverse literacies including speaking, } \\
\text { listening, viewing and creating. } \\
\text { The amount of interaction with my } \\
\text { peers (fellow students) in MAT was }\end{array}$ & na & na & na & $.781 * *$ \\
\hline
\end{tabular}
appropriate.

MAT was difficult to use. presentations of health problems. helped me to understand presentation and assessment of headache na commentary).

I fully utilised the opportunity that MAT offered. complexity of the drafting processes involved in writing.

Using MAT encouraged use of diverse literacies including speaking, listening, viewing and creating.

*. Correlation is significant at the 0.05 level (2-tailed). 
LEMON, COLASANTE, CORNEILLE \& DOUGLAS

**. Correlation is significant at the 0.01 level (2-tailed). 